\title{
Modelling Hypertension and Risk Factors among Adults Using Ordinal Logistics Regression Model.
}

\section{Monday Osagie ${ }^{1,2}$ Adenomon \& Daniel Owoicholofu ${ }^{1}$ John}

\author{
1. Department of Statistics \& NSUK-LISA Stat Lab \\ Nasarawa State University, Keffi (NSUK), Nasarawa State, Nigeria. \\ 2. Foundation of Laboratory for Econometrics and Applied Statistics of Nigeria (FOUND- \\ LEAS-IN-NIGERIA) \\ adenomonmo@nsuk.edu.ng; danielojohn@yahoo.com; +2347036990145
}

\begin{abstract}
There is high prevalence of hypertension and is rapidly increasing around the world, despite the intervention programme implemented, this study aimed at estimating the prevalence rate, test of association between hypertension and risk factors and model hypertension rate. Data used was obtained from the health record of Federal Medical Centre, Keffi from January 2016 - January 2019. Ordinal logistic regression model was used; Model Fitting Information, Goodness-of-Fit, Pseudo R-Square and Test of Parallel Lines are fitted to the data sets to test the accuracy and correctness of the model. The results indicated that the overall prevalence of hypertension rate is high at 36.4\%, among the adult population, body mass index and gender are statistically significant, and Age is not significant in the study. Individuals that are overweight are more likely to be hypertensive compare to other weights. At age $40-49$ years which have the highest rate of $26.5 \%$ and the odd ratio is 0.75 compared to others. One year increase in age $30-39$, the cumulative odd of being hypertensive is 0.91 while other independent variables are held constant. The odd ratio of female being hypertensive is 0.85 , therefore the females are more likely to be hypertensive with $54.4 \%$ compared to the males at $45.6 \%$. There is no presence of multicolinearity among the variables and Logit models were formulated to calculate probabilities of the various possible outcomes.
\end{abstract}

Key words; Hypertension, Risk, Factors, Ordinal Logistics Regression, Odd Ratio

\subsection{Introduction}

According to records National Bureau of Statistics in 2019, Nigeria has a growing population of about 200 million people and this has placed it seventh, and it is considered as the most populous Black Country in the world. Nigeria is one of the many developing countries where the health services have focused on treating infectious diseases, such as malaria, typhoid and tuberculosis 
etc. but in recent years, non-communicable conditions have become an increasing problem which affect many (WHO 2013).

Previous research findings revealed that hypertension is responsible for $45 \%$ of death due to heart disease and $51 \%$ of death due to stroke worldwide, and billions of people being affected globally (Addo, Smeeth \& Leon, 2007; Kearney, Whelton, Reynolds, Muntner \& Whelton, 2004; WHO, 2013). In the case of Nigeria, hypertension is the most common cardiovascular disease reported with the death rate of $13.62 \%$ per 100,000 population as at 2014 (Ogah, 2013; WHO 2014).

This paper modelled hypertension relation to some selected risk factors among adults using ordinal logistic regression. The risk factors are Body Mass Index, Age and Gender.

\subsection{Empirical Review of Previous Studies}

Empirical review of previous related studies was carried out in this section

Okechukwu et al (2012) carried out a study on Blood pressure, prevalence of hypertension and hypertension related complications in Nigeria. The study revealed that the prevalence rate of hypertension ranges from $8 \%$ to $46.4 \%$. The study concluded that hypertension is more common in the rural settings than the urban.

In another study, Baeta (2015) conducted a multivariate time series analysis of hypertension and heart disease. The study employed the Vector Autoregressive (VAR) model and the forecast for year 2015 predicts a slight increase for heart disease cases while the monthly forecast of hypertension and disease is at the highest for September to December.

Kirubel \& Mojgan (2015) studied the Epidemiology of Hypertension Stages in Ghana and South Africa and some factors associated with Hypertension stages. The study revealed that the 
prevalence of prehypertension and hypertension in Ghana was $30.7 \%$ and $42.4 \%$, and that of South Africa was $29.4 \%$ and $46 \%$ respectively.

Ikeloluwapo et al. (2016) investigated the Prevalence of hypertension and associated Factors among Residents of Ibadan - North local Government Area of Nigeria. A descriptive cross sectional design was used involving 806 respondents. The study employed binary logistic regression model, descriptive statistics and chi-square test. The result of the binary logistic regression revealed that hypertension was associated significantly with age group 30 - 49years and, 50 years and above and with overweight patients.

\subsection{Method and Methodology}

Secondary data is used; a total of 1304 sample size was obtained from the health record of Federal Medical Centre keffi, Nasarawa State from the period of January 2016 to January 2019.

\subsection{Dependent variable}

The response variable of this study is the hypertension status of patient between the ages of 20 to 89. It is categorized into five ordinal categories: Normal $(<120 / 80 \mathrm{mmHg})$, Pre-hypertensive $(120-139 / 80-89 \mathrm{mmHg})$, Hypertension Stage one $(140-159 / 90-99 \mathrm{mmHg})$, Hypertension stage two $(160$ - 179/100 - $119 \mathrm{mmHg})$ and Hypertensive crisis (>180/ $120 \mathrm{mmHg})$.

Description of the dependent variable

\begin{tabular}{|l|l|l|}
\hline Response variable & Value of the levels & Type \\
\hline Hypertension Levels & 1=Normal & Ordinal \\
& 2=Prehypertension. & \\
& 3=Hypertension stage one. & \\
\hline
\end{tabular}




$$
\begin{aligned}
& \text { 4=Hypertension stage two. } \\
& \text { 5= Hypertensive crisis }
\end{aligned}
$$

Source: The seventh report of joint national committee on prevalence, dictation, evaluation and treatment of high blood pressure. JAMA 203;289:2560-70

\subsection{Independent Variables}

Description of the independent variables

\begin{tabular}{|l|l|l|}
\hline Predictors name & Value of level Predictors & Type \\
\hline AGE & $0=20-29,1=30-39$, & Ordinal \\
& $2=40-49,3=50-59$, & \\
$4=60-69,5=70-79$, & \\
& $6=80-89 . \quad<18.5$, & Ordinal \\
\hline BMI & underweight = & \\
& normal weight $=18.5-$ & \\
& 24.9, & \\
& normal weight $=25.0-$ & \\
& 29.9, & Binary \\
& obese $\geq 30.0$ & \\
\hline GENDER & $0=$ Female, 1= Male & \\
\hline
\end{tabular}

BMI Source: American Heart Association (2019)

\subsection{Model Specification}

Assumptions of Ordinal Logistics Regression Model are as follows:

1. Dependent variable should be measured at the ordinal level. 
2. One or more independent variables are continuous, ordinal or categorical.

3. There should be no multicollinearity.

4. Presence proportional odds.

\subsection{Ordinal Logistic Regression (Proportional Odds) Model}

Walker and Duncan (1967) was first to introduce the proportional odds model and later described in more details by McChullagh (1980). The Proportional Odds Model is used for modeling the response variable that has more than two levels with $K$ set of explanatory variables by defining the cumulative probabilities, cumulative odds and cumulative logits.

Consider $P(Y=j / X)=P, j=1,2 \ldots, j-1$ and the cumulative probability can be defined as

$$
\pi_{j}(x)=P(Y \leq j / X)=P_{1}+P_{2}+\ldots+P_{j}, j=1,2, \ldots, j-1
$$

$\pi_{j}(x)$, is the probability of being at or below category $\mathrm{j}$, given that of $\mathrm{K}$ set of predictors. The odds of the cumulative probability of the response variable for the $J-1$ categories

$$
\operatorname{odds}\left[\pi_{j}(x)\right]=\frac{\pi_{j}(x)}{1-\pi_{j}(x)}, j=1,2 \ldots, j-1
$$

The logarithm of the odds first $\mathrm{j}-1$ cumulative probability

$$
\operatorname{In}\left(\text { odds }\left[\pi_{j}(x)\right]\right)=\operatorname{In}\left[\frac{\pi_{j}(x)}{1-\pi_{j}(x)}\right], j=1,2, \ldots, j-1
$$

Then Logit transformation of $\mathrm{j}_{\mathrm{j}}(\mathrm{X})$ cumulative probability of the response is applied which uses the logistic regression function as 


$$
\begin{aligned}
& \pi_{j}(X)=P(Y \leq j / X)=\frac{\exp \left(\alpha_{j}-\left(\beta_{1} X_{1}+\ldots+\beta_{K} X_{K}\right)\right)}{1+\exp \left(\alpha_{j}-\left(\beta_{1} X_{1}+\ldots+\beta_{K} X_{K}\right)\right)} \\
& \operatorname{In}\left[\frac{P(Y \leq j / X)}{1-P(Y \leq j / X)}\right]=\operatorname{In}\left[\frac{\pi_{j}(X)}{1-\pi_{j}(X)}\right]=\alpha_{j}-\left(\beta_{1} X_{1}+\ldots+\beta_{K} X_{K}\right)
\end{aligned}
$$

It is equivalent to

$$
\operatorname{Logit}[P(Y \leq j / X)]=\alpha_{j}-\sum_{K=1}^{K} \beta_{K} X_{K}, j=1,2, \ldots, j-1
$$

$\alpha_{j}$ represents the threshold value and which the values do not depend on the values of the independent variables, the $\beta_{k}$ 's are the logistic regression coefficients.

\subsection{Test of Overall Model Fit}

\subsubsection{Deviance and Likelihood Ratio Test}

Given $\mathrm{D}=-2(\log$ likelihood of the fitted model $)$

where $\mathrm{D}$ represent the deviance. On the other hand, the log of this likelihood ratio test will produce negative value. Hence, smaller values indicated a better fitted model as it deviate less from the saturated model.

\subsubsection{Checking of Model Adequacy}

\subsection{2a Wald Test}

The Wald test assess the significance of explanatory variables in the model and is given as:

$$
W=\left[\frac{\beta_{t}}{S E\left(\beta_{t}\right)}\right]^{2}
$$


Under the null hypothesis $H_{0}=\beta_{i}=0,1, \ldots, k$ and $W$ has a chi-square distribution with one degree of freedom (Agresti,1990).

\subsection{2b Goodness of Fit}

Goodness of fit in a statistical model described how well the model fits a set of data (Liu et al 2016). The Pearson statistics for testing goodness of fit is given as

$$
\chi^{2}=\left[\frac{(O-E)^{2}}{E}\right]
$$

Where $\chi^{2}=$ Chi-square goodness of fit test, $\mathrm{O}=$ Observed value, $\mathrm{E}=$ Expected value

\subsection{2c Pseudo R- Square}

The Pseudo R-Square summaries the proportion of variance in the outcome that can be accounted for by the explanatory variable. A Larger $R^{2}$ values indicate that more of the variation in the outcome can be explained up to a maximum of 1.

\subsection{Analysis and Results}

4.1 Multicollinearity diagnosis

\begin{tabular}{|c|c|c|c|c|c|c|c|}
\hline \multirow[b]{3}{*}{ Model } & \multicolumn{5}{|c|}{ Coefficients $^{a}$} & & \\
\hline & \multicolumn{2}{|c|}{$\begin{array}{c}\text { Unstandardized } \\
\text { Coefficients }\end{array}$} & \multirow{2}{*}{$\begin{array}{c}\text { Standardized } \\
\text { Coefficients } \\
\text { Beta } \\
\end{array}$} & \multirow[b]{2}{*}{$\mathrm{T}$} & \multirow[b]{2}{*}{ Sig. } & \multicolumn{2}{|c|}{ Collinearity Statistics } \\
\hline & $\mathrm{B}$ & Std. Error & & & & Tolerance & VIF \\
\hline (Constant) & .204 & .200 & & 1.020 & .308 & & \\
\hline BMI & .070 & .007 & .262 & 9.617 & .000 & .947 & 1.056 \\
\hline gender1 & -.161 & .053 & -.083 & -3.049 & .002 & .947 & 1.056 \\
\hline age1 & -.001 & .016 & -.002 & -.079 & .937 & .998 & 1.002 \\
\hline
\end{tabular}

a. Dependent Variable: hypertensionlevel 
There is presence of multicollinearity if the VIF value do not lie between 0 to 10 . Based on the coefficients of the output, the collinearity statistics obtained VIF are 1.056, 1.056 and 1.002 therefore since the value obtained is between 1 to 10 , it is concluded that there is no presence of multicollinearity.

\subsection{Prevalence Rate of Hypertension}

Prevalence of Hypertension in Females

$$
\begin{aligned}
\text { Prevalence } & =\times 100 \\
\text { Prevalence } & =\quad \times 100 \\
& =19.6 \%
\end{aligned}
$$

\section{Prevalence of Hypertension in Males}

$$
\begin{aligned}
\text { Prevalence } & =\times 100 \\
\text { Prevalence } & =\times 100 \\
& =16.6 \%
\end{aligned}
$$

The total prevalence rate is given as

$$
\begin{aligned}
\text { Prevalence } & =\times 100 \\
& =\times 100 \\
& =36.4 \%
\end{aligned}
$$


The females have high prevalence rate of $19.6 \%$ compared to the males at $16.6 \%$. The prevalence of hypertension is $36.4 \%$ in the period of study under consideration

\subsection{Test of Association}

\section{Hypertension and Age}

Is there significant association between hypertension and the Age?

From the cross tabulation result between grouped age and hypertension category output, it is observed that 111 patients of age $40-49$ at $24.3 \%$ are pre-hypertensive, the highest is said to be hypertensive at stage one of age $30-39$ with 89 patients at $29.2 \%$. The total highest figure is still at age $40-49$ with a total of 345 people at $26.5 \%$, follow by 247 of age between $50-59$ at $18.9 \%$

Chi-square test between grouped age hypertension category output

\begin{tabular}{lr|r|r} 
& & & \multicolumn{1}{c}{ Asymptotic } \\
& & & $\begin{array}{c}\text { Significance (2- } \\
\text { sided) }\end{array}$ \\
\hline Palue & Df & 28 & .602 \\
\hline Learson Chi-Square & $25.478^{\mathrm{a}}$ & 28 & .546 \\
\hline Nikelihood Ratio & 26.486 & 28 & \\
\hline
\end{tabular}

a. 7 cells $(17.5 \%)$ have expected count less than 5 . The minimum expected count is .04 .

The null hypothesis is accepted the null hypothesis and conclude that there is no significant association between age and the hypertension status with value of $\mathrm{p}(0.602>0.05)$. 


\section{Hypertension and Body mass index}

Is there significant relationship between hypertension and body mass index (BMI)?

From the output of the cross tabulation between grouped body mass index and hypertension category revealed that 215 persons at $53.8 \%$ that are overweight are hypertensive at stage one, and 192 persons at $41.6 \%$ are pre-hypertensive, this follow by 188 persons at $55.8 \%$ are hypertensive at stage two. It shows that the tendency of overweighed patients is higher than obsessed patients at $44.3 \%$ and $36.1 \%$ respectively. It also revealed a grand total of 665 numbers of persons at $51.0 \%$ that are overweight are hypertensive which is higher than all other BMI's followed by patients of normal weight at $35.1 \%$.

\begin{tabular}{lr|r|r} 
& & & \multicolumn{1}{c}{ Chi-Square Tests } \\
& & & $\begin{array}{c}\text { Significance (2- } \\
\text { sided) }\end{array}$ \\
\hline Value & df & 16 & .000 \\
\hline Pearson Chi-Square & $118.488^{\mathrm{a}}$ & 16 & .000 \\
\hline Likelihood Ratio & 109.479 & 16 & \\
\hline N of Valid Cases & 1304 & & \\
\hline
\end{tabular}

a. 7 cells $(28.0 \%)$ have expected count less than 5 . The minimum expected count is .04 .

The chi square test from the test of association between body mass index and hypertension level, shows that the pvalue $(0.000<0.05)$. This concludes that there is a strong significant relationship between BMI and hypertension. This shows that BMI lead to hypertension.

\section{Hypertension and Gender}

Is there significant relationship between hypertension and gender? 
Considering the cross tabulation between gender and hypertension category output, males coded as 1 while females as 0 . The males are more pre-hypertensive with 235 patients at $52.1 \%$ compared to females of 216 patients at $47.9 \%$. A total number of 217 females at $64.8 \%$ are at hypertension stage 2 which is more compared to the males at 118 at $35.2 \%$ in the same stage. The grand total shows that 709 females are hypertensive at $54.4 \%$ and is higher than the males with 595 at $45.6 \%$.

\begin{tabular}{|c|c|c|c|}
\hline \multicolumn{4}{|c|}{ Chi-Square Tests } \\
\hline & Value & Df & $\begin{array}{c}\text { Asymptotic } \\
\text { Significance (2- } \\
\text { sided) }\end{array}$ \\
\hline Pearson Chi-Square & $27.432^{\mathrm{a}}$ & 4 & .000 \\
\hline Likelihood Ratio & 27.689 & 4 & .000 \\
\hline $\mathrm{N}$ of Valid Cases & 1304 & & \\
\hline
\end{tabular}

a. 0 cells $(0.0 \%)$ have expected count less than 5 . The minimum expected count is 22.81 .

The chi square test output has the significant level as 0.000 , value $p<0.05$. This indicates that there is a strong association between gender and hypertension. Therefore gender lead to hypertension in this study under reference.

\subsection{Ordinal Logistic Regression Model}

Ordinal logistics regression analysis

\begin{tabular}{|c|c|c|c|c|c|c|c|c|}
\hline \multicolumn{9}{|c|}{ Parameter Estimates } \\
\hline & & \multirow[b]{2}{*}{ Estimate } & \multirow[b]{2}{*}{ Std. Error } & \multirow[b]{2}{*}{ Wald } & \multirow[b]{2}{*}{$\mathrm{df}$} & \multirow[b]{2}{*}{ Sig. } & \multicolumn{2}{|c|}{$\begin{array}{l}\text { 95\% Confidence } \\
\text { Interval }\end{array}$} \\
\hline & & & & & & & $\begin{array}{l}\text { Lower } \\
\text { Bound }\end{array}$ & $\begin{array}{l}\text { Upper } \\
\text { Bounc }\end{array}$ \\
\hline \multirow[t]{2}{*}{ Threshold } & $\begin{array}{l}\text { [hypertension_level = } \\
\text { hypertension crisis] }\end{array}$ & -4.098 & .429 & 91.092 & 1 & .000 & -4.939 & -3.256 \\
\hline & $\begin{array}{l}\text { [hypertension_level = } \\
\text { hypertension stage1] }\end{array}$ & -1.655 & .411 & 16.212 & 1 & .000 & -2.460 & -.840 \\
\hline
\end{tabular}




\begin{tabular}{|c|c|c|c|c|c|c|c|c|}
\hline & $\begin{array}{l}\text { [hypertension_level = } \\
\text { hypertension stage2] }\end{array}$ & -.587 & .409 & 2.064 & 1 & .151 & -1.388 & .214 \\
\hline & $\begin{array}{l}\text { [hypertension_level = } \\
\text { normal] }\end{array}$ & -.417 & .409 & 1.043 & 1 & .307 & -1.218 & .384 \\
\hline \multirow[t]{15}{*}{ Location } & {$[\mathrm{Nage}=]$} & -.250 & 1.832 & .019 & 1 & .892 & -3.840 & 3.340 \\
\hline & {$[$ Nage $=0$} & -.081 & .293 & .076 & 1 & .783 & -.656 & .494 \\
\hline & {$[$ Nage $=1]$} & .027 & .275 & .010 & 1 & .021 & -.512 & .566 \\
\hline & {$[$ Nage $=2]$} & -.294 & .265 & 1.229 & 1 & .268 & -.814 & .226 \\
\hline & {$[$ Nage $=3]$} & -.246 & .272 & .814 & 1 & .367 & -.779 & .288 \\
\hline & {$[$ Nage $=4]$} & -.093 & .285 & .106 & 1 & .044 & -.652 & .466 \\
\hline & {$[$ Nage $=5]$} & -.201 & .292 & .474 & 1 & .491 & -.772 & .371 \\
\hline & {$[$ Nage $=6]$} & $0^{\mathrm{a}}$ & . & . & 0 & & . & \\
\hline & [NBMI=noer weight] & -2.418 & 1.938 & 1.558 & 1 & .212 & -6.216 & 1.379 \\
\hline & $\begin{array}{l}{[\mathrm{NBMI}=\text { normal }} \\
\text { weight] }\end{array}$ & -.678 & .331 & 4.195 & 1 & .041 & -1.327 & -.029 \\
\hline & {$[\mathrm{NBMI}=$ obese $]$} & -1.112 & .354 & 9.893 & 1 & .002 & -1.805 & -.419 \\
\hline & [NBMI=over weight] & -.871 & .327 & 7.090 & 1 & .008 & -1.512 & -.230 \\
\hline & [NBMI=under weight] & $0^{\mathrm{a}}$ & & & 0 & & . & \\
\hline & [gender=f] & -.164 & .105 & 2.443 & 1 & .118 & -.369 & .042 \\
\hline & [gender=m] & $0^{\mathrm{a}}$ & . & & 0 & & . & \\
\hline
\end{tabular}

Link function: Logit.

a. This parameter is set to zero because it is redundant.

\section{Interpretation of Proportional Odd model}

The age group between $30-39$ and $60-69$ are statistically significant likewise normal BMI,

Obese and overweight are found to be statistically associated with hypertension stages.

Only age $30-39$ is found to positively affect hypertension stages therefore it has higher contribution to hypertension while the other risk factors stages negatively affect hypertension stages have lower contribution to risk of developing hypertension.

Threshold1value indicates the probability of hypertension crisis, hypertension stage one, hypertension stage two versus normal, thus it is the log odd for age $80-89$, underweight and 
gender (male) at mean value. Similarly, threshold 2 is the $\log$ odd of hypertension crisis, hypertension stage one, hypertension stage two versus normal. Age group between 30 - 39 is positively associated with Hypertension stage and its coefficient is 0.27 which is significantly different than zero using wald statistic. Age is a continuous variable, age 30- 39 subjects has log odds of being in a higher hypertensive stage would increase by 0.27 relative to other age group and other independent variables held constant. . In term of odds ratio, age 30 - 39 have (using R) $\exp (0.27)=1.309964,1.3$ times more likely to be in hypertension crisis, hypertension stage 1 , stage 2 and normal relative to other ages. And age $60-69$ is statistically significant, the log odd of being hypertensive is -.093 and the odd ratio is (using $\mathrm{R}$ ) $\exp (-.093)=0.9111935$. i.e one year increase in age 30 - 39, the cumulative odd of being hypertensive is 0.91 while other independent variable are held constant.

BMI has four category, The normal weight with $\mathrm{BMI}<18.5-24.5$ has a log odd of-.678and the odd ratio is0.5076312 have more chance of being hypertensive compared to being underweight. Obese with $\mathrm{BMI} \geq 30$ has a log odd of -1.112 being hypertensive would increase by and the odd ratio of (using $\mathrm{R}$ ) $\exp (-1.112)=0.3289005$ which is significant than zero. Over weight with BMI 25.0 - 29.9 has log odd of -.871 and the odd ratio is (using $\mathrm{R}) \exp (-.871)=0.4185328$.

The intercepts is represented as the threshold coefficients (in terms of a logit) therefore the hypertension status is predicted into the four categories model equations

The threshold $\left(\alpha_{\mathrm{j}}\right)$ is what differentiates the interpretation of ordinal logistic regression model and ordinary least square regression equation.

The estimated coefficients in the ordinal logistic regression model represent the change in the log odds for one unit increase in the independent variable. 
The ordinal logistic regression model is given as

$$
\begin{aligned}
& \text { Where } \mathrm{j}=1,2,3,4 \\
& {[P(Y \leq j \mid X)]=\alpha_{j}+B_{1} X_{1}+B_{2} X_{2}+B_{3} X_{3}}
\end{aligned}
$$

The equation model for being hypertension crisis is

$$
\operatorname{In}\left(\theta_{1}\right)=-4.098-.081 x_{1}+.027 x_{2}-.294 x_{3}-.246 x_{4}-.093 x_{5}-.201 x_{6}-.678 x_{7}-1.112 x_{8}-.871 x_{9}-.164 x_{10}
$$

The equation model for being in hypertension stage one is

$$
\operatorname{In}\left(\theta_{2}\right)=-1.655-.081 x_{1}+.027 x_{2}-.294 x_{3}-.246 x_{4}-.093 x_{5}-.201 x_{6}-.678 x_{7}-1.112 x_{8}-.871 x_{9}-.164 x_{10}
$$

The equation model for being in hypertension stage two is

$$
\operatorname{In}\left(\theta_{3}\right)=-.587-.081 x_{1}+.027 x_{2}-.294 x_{3}-.246 x_{4}-.093 x_{5}-.201 x_{6}-.678 x_{7}-1.112 x_{8}-.871 x_{9}-.164 x_{10}
$$

The equation model for being normal is

$$
\operatorname{In}\left(\theta_{4}\right)=-.417-.081 x_{1}+.027 x_{2}-.294 x_{3}-.246 x_{4}-.093 x_{5}-.201 x_{6}-.678 x_{7}-1.112 x_{8}-.871 x_{9}-.164 x_{10}
$$

From the four ordered dependent variable of hypertension level, all the 0's are the reference point since the first estimate is bigger than zero, a positive beta meaning a high rating. 


\subsection{Test of Model Adequacy}

\begin{tabular}{|c|c|c|c|c|}
\hline \multicolumn{5}{|c|}{ Test of Parallel Lines ${ }^{a}$} \\
\hline Model & $\begin{array}{c}-2 \text { Log } \\
\text { Likelihood }\end{array}$ & Chi-Square & $\mathrm{df}$ & Sig. \\
\hline Null Hypothesis & 659.083 & & & \\
\hline General & $467.728^{b}$ & $191.355^{c}$ & 36 & .000 \\
\hline
\end{tabular}

The null hypothesis states that the location parameters (slope coefficients) are the same across response categories.

a. Link function: Logit.

b. The log-likelihood value cannot be further increased after maximum number of step-halving.

c. The Chi-Square statistic is computed based on the log-likelihood value of the last iteration of the general model. Validity of the test is uncertain.

The test of parallel lines table shows the value of $\mathrm{p}<0.05$, therefore it is statistically significant. This shows the independent variables and logit are the same for all logits. The null hypothesis therefore states that the slope coefficients are the same across the response categories in the model and the lines are parallel. It is concluded that the assumption holds.

\begin{tabular}{lr|r|r}
\multicolumn{3}{c}{ Goodness-of-Fit } \\
& Chi-Square & \multicolumn{1}{c}{ Df } & \multicolumn{1}{c}{ Sig. } \\
\hline Pearson & 272.169 & 204 & .001 \\
\hline Deviance & 273.996 & 204 & .001 \\
\hline
\end{tabular}

Link function: Logit.

The Pearson and deviance statistic is considered significant if the significant level is greater than (>) 0.05 . The result from the data suggest that the model does not fit very well because the significant level is $\mathrm{p}(0.001<0.05)$. it is considered that the chi-square is highly likely to be significant when your sample size is large. 


\section{Model Fitting Information}

\begin{tabular}{l|r|r|r|r} 
Model & \multicolumn{1}{c|}{$\begin{array}{c}-2 \text { Log } \\
\text { Likelihood }\end{array}$} & Chi-Square & \multicolumn{1}{c}{ Df } & \multicolumn{1}{c}{ Sig. } \\
\hline Intercept Only & 685.261 & & & \\
\hline Final & 659.083 & 26.177 & 12 & .010 \\
\hline
\end{tabular}

Link function: Logit.

Since $\mathrm{p}$ value $0.010<0.05$ the chi square statistics for model fitting information is considered statistically significant, which indicate that the model fits very well. The Final model gives a significant improvement over the baseline intercept-only model. This tells you that the model gives better predictions than the null model.

\section{Pseudo R-Square}

\begin{tabular}{ll} 
Cox and Snell & .020 \\
\hline Nagelkerke & .021 \\
\hline McFadden & .007 \\
\hline
\end{tabular}

Link function: Logit.

The Pseudo R-square i.e the Cox and Snell, Nagelkerke and McFadden values do not have the same interpretation as standard R-squared values from OLS regression. The pseudo $\mathrm{R}^{2}$ values indicate that only relatively small proportion of the variation between hypertension and the risk factors are explained in the variable. This is what we would expect because there are many risk factors that are not considered. 


\subsection{Binary Logistic Regression Analysis}

Table: 4.8 Binary Classification Table

\section{Classification Table}

a. The cut value is .500

\begin{tabular}{|r|r|r|r|r|r|r|}
\hline & & & \multicolumn{2}{|c|}{ Predicted } \\
\hline & & & \multicolumn{2}{|c|}{ Binhyp_level } & \multicolumn{2}{|c|}{$\begin{array}{l}\text { Percentage } \\
\text { Correct }\end{array}$} \\
\hline Step 1 & Binhyp_level & hyperten & 1254 & 0 & 100.0 \\
\hline & & not hype & 50 & & 0 & .0 \\
\hline & Overall Percentage & & & & & 96.2 \\
\hline
\end{tabular}

When the cut value is equal 0.500 or more there is a probability of an event occurring and less than 0.5 as the event not occurring. The classification table revealed there is a significant probability of being hypertensive.

\begin{tabular}{|c|c|c|c|}
\hline \multicolumn{4}{|c|}{ Model Summary } \\
\hline Step & -2 Log likelihood & $\begin{array}{c}\text { Cox \& Snell R } \\
\text { Square }\end{array}$ & $\begin{array}{c}\text { Nagelkerke R } \\
\text { Square }\end{array}$ \\
\hline 1 & $402.670^{a}$ & .016 & .059 \\
\hline
\end{tabular}

The table of model summary contain cox \& snell R square and Nagelkerke R square, this show explained variation in dependent variable based on the model ranges from $1.6 \%$ to $5.9 \%$. It is preferable to report the Nagelkerke $\mathrm{R}^{2}$ value. This is what we could expect because more variables are not considered. 


\subsection{Variables in Binary Logistic Equation}

\begin{tabular}{|c|c|c|c|c|c|c|c|}
\hline \multicolumn{8}{|c|}{ Variables in the Equation } \\
\hline & & $\mathrm{B}$ & S.E. & Wald & $\mathrm{Df}$ & Sig. & $\operatorname{Exp}(B)$ \\
\hline \multirow{15}{*}{ Step $1^{a}$} & New age & & & 5.775 & 7 & .566 & \\
\hline & New age(1) & .164 & 40546.945 & .000 & 1 & 1.000 & 1.178 \\
\hline & New age(2) & 18.530 & 5346.019 & .000 & 1 & .997 & 111549131.488 \\
\hline & New age(3) & 18.397 & 5346.019 & .000 & 1 & .997 & 97619867.848 \\
\hline & New age(4) & 17.609 & 5346.019 & .000 & 1 & .997 & 44408095.500 \\
\hline & New age (5) & 17.864 & 5346.019 & .000 & 1 & .997 & 57289298.947 \\
\hline & New age $(6)$ & 17.734 & 5346.019 & .000 & 1 & .997 & 50319269.763 \\
\hline & New age (7) & 18.178 & 5346.019 & .000 & 1 & .997 & 78486419.889 \\
\hline & New BMI & & & 6.667 & 4 & .155 & \\
\hline & New BMI(1) & -17.830 & 40192.970 & .000 & 1 & 1.000 & .000 \\
\hline & New BMI(2) & -.025 & .765 & .001 & 1 & .974 & .976 \\
\hline & New BMI(3) & -.963 & .940 & 1.048 & 1 & .306 & .382 \\
\hline & New BMI(4) & -.769 & .774 & .986 & 1 & .321 & .464 \\
\hline & gender(1) & -.383 & .306 & 1.570 & 1 & .210 & .682 \\
\hline & Constant & -20.598 & 5346.019 & .000 & 1 & .997 & .000 \\
\hline
\end{tabular}

a. Variable(s) entered on step 1: New age, New BMI, gender.

The wald test statistics and the corresponding significant level column is used to determine statistical significance of all the independent variables, with value of $p<0.005$ are of statistical significant. The equation is given as

$\log i t($ hyp $)=-20.598+.164 x_{1}+18.530 x_{2}+18.397 x_{3}+17.609 x_{4}+17.864 x_{5}+17.734 x_{6}+18.178 x_{7}-17.830 x_{8}-.025 x_{9}-.963 x_{10}-.769 x_{11}-.383 x_{12}$

The variables in the binary equation output is used to predict the probability of an event occurring based on one unit in the independent variable when all independent are kept constant. 


\subsection{Discussion of Results}

This study prevalence of hypertension and risks factors among adults using the ordinal logistic regression model is aimed at estimating the prevalence of hypertension, testing for the association between the ordinal dependent variable and independent variables and to model hypertension in Nasarawa state. In this study the female are more hypertensive compared to the male with $54.4 \%$ and $45.6 \%$ respectively. The overall hypertension prevalence is $36.2 \%$ which is in line with WHO statement that African region has the highest prevalence rate of hypertension with the estimate of $46 \%$ (WHO, 2013). It is similar to $44 \%$ prevalence rate of hypertension in rural communities in delta state conducted by ofili et al (2015). it was discovered that increasing age, body mass index and high salt intake are the major risk factors of hypertension using multivariate logistic regression analysis.

From the test of association in this study, chi-square was used and age is not significant, body mass index and gender are found to be statistically significant which tells that they are major cause of hypertension. Patients of age $40-49$ years have the highest rate of hypertension at $24.3 \%$ are pre-hypertensive followed by $18.9 \%$ of age $40-49$ years. The total highest figure is still at age $40-49$ with a total of 345 people at $26.5 \%$, follow by 247 of age between $50-59$ at $18.9 \%$.

Body mass index is also statistically significant with $\mathrm{p}<0.05$. From the study, a total of $51.0 \%$ of patients are said to be overweight, which is confirmed that being overweight leads to hypertension. The males are more pre-hypertensive with 235 patients at $52.1 \%$ compared to females of 216 patients at $47.9 \%$. A total number of 217 females at $64.8 \%$ are at hypertension stage 2 . This is similar to a study carried out by Tee et al (2010) on the prevalence of hypertension 
and its associated risk factors in two rural communities in Malaysia, he applied logistic regression analysis and found out that age, history of alcohol consumption, and BMI were independently associated with hypertension which important risk factors associated with the prevalence of hypertension.

The highest total number of patients that are hypertensive are said to be overweight at $50.8 \%$ which is more for patients been normal weight to be hypertensive at $35.1 \%$. This finding is consistent with the result obtained by ikeoluwapo et al (2016) in the study; prevalence of hypertension and associated factors among residents of Ibadan-north, shows that there is a strong association between BMI and hypertension with value of $\mathrm{p}<0.01$. it was revealed that obese respondents have the highest prevalence of $51.4 \%$ while underweight had the lowest prevalence of $28.6 \%$.

Gender is significant in the study because value of $\mathrm{p}>0.05$. From the study, it shows that the females are more hypertensive than the males with the total rates of $54.4 \%$ and $45.6 \%$ respectively, therefore it is confirmed that the female tends to be hypertensive than the male in the study.

\subsection{Recommendations}

Based on the results of this study, we recommend the following interventions be put in place in Nasarawa state to reduce the health burden of hypertension in the state.

The following recommendations are suggested;

1. Since hypertension is a modifiable risk factor associated with Age, BMI and Gender, it is important that sporting activities be introduced to manage BMI in the treatment of hypertensive patients and age range with higher risk. 
2. The government should provide good and functioning healthcare centers were treatment of hypertension and other non-communicable diseases are taking seriously.

3. People should be encouraged to visit the hospital frequently for medical checkup, upon being hypertensive, must take their medication just as prescribed by a doctor and good follow-up should be done.

4. Proper sensitization of the public on hypertension should be carried out on the radio stations, sharing of flyers in motor parks and public announcement in town hall meetings on healthy living.

\section{REFERENCES}

Adeloye D, Basquill C, Aderemi AV, Thompson JY and Obi FA (2015). An estimate of the prevalence of hypertension in Nigeria: a systematic review and meta-analysis.

Agresti A. (2002) Categorical Data Analyisis.Wiley series in probability and mathematical statistics. John Wiley and Sons, New York, NY.

Birhane zelalem (2014) Risk factors for Anaemia Levels among Women of Reproductive age in Ethiopia: A partial Proportional Odds Model approach. A Master of Science degree. Department of statistics. Addis Ababa University, Ethiopia.

Brant R 1990. Assessing proportionality in the proportional odds model for ordinal logistic regression. Biometrics 46: 1171-1178.

Chobanian AV, Bakri GL, Black HR, Cushman WC, Green LA, Izzo JL, Roccella EJ (2003) Seventh report of the joint national committee on prevension, detection, evaluation and treatment of high blood pressure. National high blood pressure education program coordinating committee. Hypertension. 42(6):1206-52.

Cox D and Snell, E. J. (1989): The Analysis of Binary Data, 2nd ed. London:

Chapman and Hall.

Das S, Rahman RM (2011) Application of ordinal logistic regression analysis in determining risk factors of child malnutrition in Bangladesh. 14;10:124. doi: 10.1186/1475-2891-10-124. 
Davies A, Catriona B, Adewale V. A, Jacqueline Y. T and Felix A. O (2014). An estimate of the prevalence of hypertension in Nigeria: a systematic review and meta-analysis. www.jhypertension.com

Ekanem US, Opara DC, Akwaowo CD (2013) High blood pressure in a semi-urban community in south-south Nigeria: a community - based study. African Health Sciences; 13(1): $56-61$.

Ikeoluwapo O Ajayi, IbukunOpeyemi Sowemimo, Onoja Matthew Akpa, Ndudi Edmund Ossai (2016) Prevalence of hypertension and associated factors among residents of Ibadan-North Local Government Area of Nigeria DOI: $10.4103 / 0189-7969.165168$.

Kadiri S (2001). A Bottle of Beer Per Day Brings Hypertension Closer'. The Nigerian Tribune, Thursday, April 19: 16.

Kathleen Abu-Saad, Angela Chetrit, Sigal Eilat-Adar, Gershon Alpert, Ahmed Atamna, Michal Gillon-Keren, Ori Rogowski, ArnonaZiv, OfraKalterLeibovici (2014) Blood Pressure Level and Hypertension Awareness and Control Differ by Marital Status, Sex, and Ethnicity: A Population-Based Study American Journal of Hypertension, Pages 1511-1520.

Kearney PM, Whelton M, Reynolds K, Muntner P, Whelton PK, He J.(2005): Global burden of hypertension: analysis of worldwide data. Lancet, 365(9455): 217223.

Kirubel Z Gebreselassie and Mojganpadyab (2015). Epidemiology of Hypertension Stage in two Countries in Sub-Sahara Africa: Factors Associated with Hypertension Stages. Int J Hypertens, 2015: 959256.

Lackland D T, Weber M A (May 2015) “Global burden of cardiovascular disease and stroke: hypertension at the core". The Canadian journal of Cardiology 31 (5): 569-71.

Mahmoud K. Okasha (2013) Prevalence Rates of Hypertension and Related Risk Factors in Palestine. International Journal of Statistical, 13, 2013;55-72.

McCullagh, Peter (1980). "Regression Models for Ordinal Data".Journal of the Royal Statistics Society. Series B ( Methodological). 42 (2): 109 - 142.

Ofili MI, Ncama BP, Sartorius B (2015) Hypertension in rural communities in Delta State, Nigeria: Prevalence, risk factors and barriers to health care. Afr J Prm Health Care Fam Med. 2015;7(1).

Okechukwu S Ogah, Ikechi Okpechi, Innocent I Chukwuonye, Joshua O Akinyemi, Basden JC Onwubere, Ayodele O Falase, Simon Stewart, and Karen Sliwa (2012). Blood pressure, 
prevalence of hypertension and hypertension related complications in Nigerian Africans: A review; 4(12): 327-340.

Onwuchekwa A. C.,. Onwuchekwa R. C, and Asekomeh E. G. (2009) "Stroke in young Nigerian adults,” Journal of Vascular Nursing, vol. 27, no. 4, pp. 98-102, 2009.

Rajeev Kumar, Jai Sankar R. (2014). An Application for ordinal logistic (propotional odds) regression model using SPSS.

The World health organisation statistics report (2012), released on 16 May 2012, highlights the growing problem of non-communicable diseases.

Walker, SH; Duncan, DB (1967)."Estimation of the probability of an event as a function of several independent variables". Biometrika. 54 : 167-178.

WHO Bulletin 2019. Global Health Observatory (GHO) data 2019. (https://www.who.int/gho/ncd/risk_factors/blood_pressure_prevalence_text/en/)

World health organisation. World health day 2013: Silent Killer, Global Public Health Crisis. WHO Campaigns; 2013 a.

World health organization report on hypertension (2019) https://www.who.int/newsroom/fact-sheets/detail/hypertension

World Health Organization (2013). A global brief on hypertension: silent killer, global public health crises (World Health Day 2013). Geneva: WHO; 2013. 